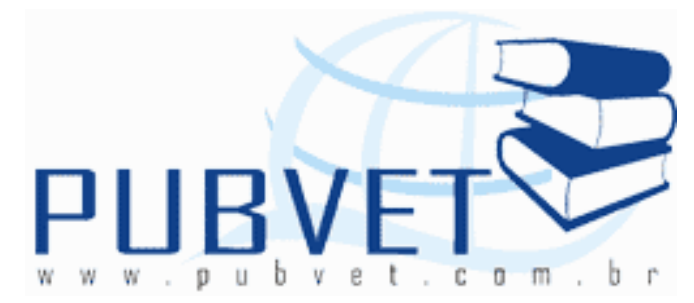

PUBVET, Publicações em Medicina Veterinária e Zootecnia.

\title{
Silagem de planta inteira de milho: pontos importantes a serem considerados
}

\footnotetext{
Marco Aurélio Factori ${ }^{1}$, Caio Tesoto Passini ${ }^{2}$, Paulo Roberto de Lima Meirelles ${ }^{3}$, Luiz Carlos Vieira Junior ${ }^{4}$, Erika Tagima Marcelo ${ }^{2}$, Marina Gabriela Berchiol da Silva ${ }^{4}$, Alan de Santana Pereira ${ }^{2}$
}

\begin{abstract}
${ }^{1}$ Aluno de Pós-doutorado do Departamento de Melhoramento e Nutrição Animal da FMVZ/UNESP/Botucatu-SP; CP: 560, distrito de Rubião Junior, CEP: 18618000,e-mail: mafactori@yahoo.com.br;

${ }^{2}$ Graduandos em Zootecnia - FMVZ/UNESP/Botucatu-SP,

e-mail: caiopassini@hotmail.com,

erika tmarcelo@hotmail.com, alansp.santana@gmail.com;

${ }^{3}$ Prof. do Departamento de Melhoramento e Nutrição Animal da FMVZ/UNESP/Botucatu, e-mail: paulom@fmvz.unesp.br;

${ }^{4}$ Alunos do Programa de Pós Graduação em Zootecnia da FMVZ/UNESP/Botucatu-SP,

e-mail: vieira zoo@hotmail.com; gabiberchiol@hotmail.com
\end{abstract}

\section{Resumo}

Sendo o milho uma planta de ciclo fotossintético $\mathrm{C}_{4}$, adapta-se muito bem ao clima tropical admitindo alta capacidade de produção de matéria seca (MS) e por apresentar características desejáveis de uma planta para ensilagem, o milho é a mais popular cultura utilizada. A cultivar é responsável, em média, 
FACTORI, M.A. et al. Silagem de planta inteira de milho: pontos importantes a serem considerados. PUBVET, Londrina, V. 6, N. 17, Ed. 204, Art. 1368, 2012.

por $50 \%$ desse rendimento final. Conseqüentemente, a escolha correta das sementes (híbridos ou cultivares, com sua respectiva textura) pode ser a razão do sucesso da cultura. Quanto à textura dos híbridos podem ser agrupadas de acordo com a textura dos grãos, classificando-se em: dentado (dent), grão duro ou cristalino (flint) e grãos semiduros ou semidentados os quais apresentam características intermediárias. Em relação ao estádio de colheita, inúmeros critérios devem ser adotados em relação à determinação do ponto ideal com o intuito de atingir o equilíbrio entre produção de massa seca por hectare e o valor nutritivo da forragem e aproveitamento. A silagem, quando adequadamente compactada favorece e acelera a fermentação anaeróbia no interior do silo. Entretanto, o processamento da forragem a ser ensilada visa melhorar a qualidade do material por meio do tratamento mecânico do grão ou da porção vegetativa. O tratamento mecânico pode ser realizado principalmente pelo esmagamento dos grãos ou cortes para diminuir a fração vegetativa da planta. A soma de todos os processos descritos, influencia a qualidade final da silagem fundamental para o desenvolvimento dos diversos sistemas de produção que a utilizam.

Palavras-chave: aproveitamento, estádio de colheita, suplementação, textura

\title{
The whole plant silage corn crop - Important points to consider
}

\begin{abstract}
Corn being a C4 plant photosynthetic cycle, it adapts well to the tropical climate assuming high production capacity of dry matter (DM) and by having the desirable characteristics of a plant for silage, corn is the most popular culture used. The cultivar is responsible on average for $50 \%$ of final yield. Therefore, the correct choice of seeds (hybrids or cultivars, with their respective texture) may be the reason for the success of the culture. The texture of the hybrids can be grouped according to the texture of the grains, sorting into: dent (dent), durum wheat or crystalline (flint) and semi-hard grains or semi-dents which show intermediate characteristics. In relation to the
\end{abstract}


FACTORI, M.A. et al. Silagem de planta inteira de milho: pontos importantes a serem considerados. PUBVET, Londrina, V. 6, N. 17, Ed. 204, Art. 1368, 2012.

harvesting stage, Several criteria must be adopted in relation to determining the ideal point in order to achieve a balance between dry matter production per hectare and nutritive value of forage utilization. The silage, when properly compressed favors and accelerates the anaerobic fermentation in the silo. However, processing of the fodder to be ensiled is to improve the quality of material by means of mechanical treatment of the grain or vegetative portion. The mechanical treatment may be accomplished mainly by crushing the grains or cuttings to reduce the fraction of the vegetative plant. The sum of all the processes described, influences the final quality of the silage fundamental to the development of different production systems that use it.

Keywords: harvesting stage, supplementation, texture, utilization

\section{Silagem de milho como volumoso}

Principalmente nas regiões Sudeste e Centro-Oeste do Brasil, as variações climáticas acarretam a estacionalidade na produção de forragem durante 0 período de inverno. Portanto, é necessário produzir durante o verão, alimento de boa qualidade e que possa ser armazenado e conservado para ser fornecido aos animais, com destaque para os ruminantes, visando um aumento na eficiência da produção de leite e carne.

Sendo o milho uma planta de ciclo fotossintético $\mathrm{C}_{4}$, adapta-se muito bem ao clima tropical admitindo alta capacidade de produção de matéria seca (Ramos et al., 2002). Por apresentar características desejáveis de uma planta para ensilagem, o milho é a mais popular cultura utilizada. Nesse contexto, Nussio et al. (2001) destacam a adaptabilidade do milho ao clima tropical, alta produtividade, teor adequado de matéria seca (MS), bom valor nutritivo, alto consumo pelos animais, baixo poder tampão e níveis adequados de carboidratos solúveis para a fermentação e sua conseqüente conservação.

Nutricionistas de todo o mundo procuram estabelecer novos parâmetros para avaliar a qualidade de forragens a fim de se conseguir incrementos na eficiência do processo de alimentação. A disponibilidade de forragens em 
quantidade e qualidade é fator determinante para que o animal exponha seu potencial máximo de produção, influenciando diretamente em sua produtividade, potencial reprodutivo e sanitário (Barbosa et al., 2007).

O rendimento de uma lavoura de milho é o resultado do potencial genético das sementes e das condições de plantio (solo, adubação e clima), bem como do manejo da cultura. A cultivar é responsável, em média, por 50\% desse rendimento final. Conseqüentemente, a escolha correta das sementes (híbridos ou cultivares, com sua respectiva textura) pode ser a razão do sucesso da cultura (Cruz et al., 2004). Na escolha de um híbrido de milho para produção de silagem almeja-se alta porcentagem de grãos, devendo-se ainda levar em consideração para qualidade dessa silagem, o valor nutritivo da porção haste - folhas e a digestibilidade do material (Nussio et al., 2001), os quais sofrem influência, principalmente pela escolha correta da textura dos materiais utilizados.

\section{Textura das cultivares de milho}

Em virtude do grande avanço no melhoramento genético são encontrados hoje no mercado variedades, híbridos duplos, triplos e simples (Cruz e Pereira Filho, 2005). Os mesmos autores ainda ressaltaram que as cultivares se diferenciam em características morfofisiológicas distintas como: arquitetura de planta, sincronismo de florescimento, empalhamento, decumbência, tolerância a estresses hídrico e térmico, tolerância às pragas e ao alumínio tóxico e eficiência no uso de nutrientes, sendo portanto, características que também devem ser consideradas na escolha da cultivar.

Quanto à textura dos híbridos, Cruz et al. (2004) afirmaram que as cultivares de milho podem ser agrupadas de acordo com a textura dos grãos, classificando-se em: dentado (dent), grão duro ou cristalino (flint) e grãos semiduros ou semidentados os quais apresentam características intermediárias. No mercado são predominantes os grãos semiduros e duros 
constituindo $93 \%$ do volume de grãos comercializados (Cruz e Pereira Filho, 2005).

Em relação às texturas dos grãos de milho, os grânulos de amido dentro das células se apresentam envoltos por uma matriz protéica que possui diferentes localizações no grão. Dessa forma, a matriz protéica acaba tendo distribuição esparsa e fragmentada no endosperma farináceo, sendo na região vítrea, densa e bem desenvolvida. Assim, há um favorecimento para um maior ataque enzimático, o que facilita a degradação do amido (Correa et al., 2002). No entanto, a interação do amido com a proteína pode reduzir sua susceptibilidade à hidrólise enzimática, reduzindo sua digestibilidade (Demarquilly e Andrieu, 1996) e, ainda, proporcionar maior dureza e consequentemente maior dificuldade de trituração ou demandar maior potência nas colhedoras de forragem.

Nesse contexto, a relação amilose:amilopectina é de grande importância na composição do amido. A proporção de amilose no grânulo de amido varia de 14 a $34 \%$, enquanto que a amilopectina representa cerca de 70 a $80 \%$ do total de amido presente nos grãos de milho (Kotarski et al., 1992). A proporção de amilose:amilopectina influencia a digestibilidade do amido. Desta forma, fontes de amido com maiores teores de amilopectina, como o grão de milho imaturo, podem apresentar maior digestibilidade (Jobim et al., 2003), sendo o estádio de colheita um fator importante neste aproveitamento.

\section{Estádios de colheita}

A linha de leite no grão pode ser um indicador para determinação do seu teor de umidade. Sulc et al. (1996) concluíram que o estádio de linha de leite do grão e o teor de matéria seca na planta inteira se correlacionam positivamente. Porém, a determinação do momento mais indicado para colheita por meio do estádio da linha de leite pode induzir a erros sob condições de veranico, déficit hídrico, presença de stay green e características das cultivares. 
FACTORI, M.A. et al. Silagem de planta inteira de milho: pontos importantes a serem considerados. PUBVET, Londrina, V. 6, N. 17, Ed. 204, Art. 1368, 2012.

Inúmeros critérios devem ser adotados em relação à determinação do ponto ideal de colheita, com o intuito de atingir o equilíbrio entre produção de massa seca por hectare e o valor nutritivo da forragem sendo este ponto ótimo tanto quanto discordantes, em função dos diferentes objetivos a serem almejados. Nussio (1991) relatou que o ponto ideal de matéria seca para colheita estaria em torno de 33 a 37\%, enquanto Cruz (1998) afirmou que seria entre 28 a $33 \%$ e Bal (1997) observou melhor desempenho em vacas alimentadas com silagens colhidas com $2 / 3$ de linha de leite no grão. Esta dispersão pode trazer diferenças inerentes à textura dos híbridos e práticas agrícolas.

A recomendação do momento ideal para colheita sempre sugeriu estádios fisiológicos mais avançados. Considerando a composição bromatológica da planta de milho, Lavezzo et al. (1997) relataram razoável flexibilidade quanto à escolha do momento de corte. Mccullough (1968) observou máximo consumo pelo animal e maior produção de MS quando o milho foi colhido no ponto farináceo-duro, sugerindo maior desempenho nestas condições.

O teor de matéria seca constitui um dos fatores mais importantes a ser considerado na avaliação da qualidade das silagens. As perdas de nutrientes por efluente são maiores à medida que a forragem ensilada apresenta alto teor de umidade (Waldo, 1976). Resultados de pesquisas sugerem redução de $1 \%$ no consumo pelo animal para cada redução percentual unitária no teor de MS das silagens (Demarquilly e Dulphy, 1977).

O enchimento do grão e a perda de digestibilidade dos componentes da haste são eventos concomitantes. A recomendação do momento ideal para colheita sempre sugeriu estádios fisiológicos mais avançados, onde fosse possível conciliar maior acúmulo líquido de biomassa, tanto de grãos como da planta toda. Blaser (1969) ressaltou que o aumento da maturidade e do teor de matéria seca foram determinantes para uma maior proporção de espigas na planta, sem, no entanto, causar alteração na concentração de NDT.

Para híbridos de texturas diferentes, em um mesmo estádio de colheita, verificam-se desempenhos produtivos distintos. Michalet Doreau e Phillipeau 
FACTORI, M.A. et al. Silagem de planta inteira de milho: pontos importantes a serem considerados. PUBVET, Londrina, V. 6, N. 17, Ed. 204, Art. 1368, 2012.

(1998); citados por Johnson (1999) observaram que no mesmo ponto de maturação, as cultivares de grãos dentados apresentaram maior degradabilidade do que as cultivares de grão duro. A perda de digestibilidade por atraso na colheita é menor nos híbridos macios (permitindo maior intervalo de colheita). Híbridos de textura dura admitem menor erro quanto ao ponto de ensilagem (colheitas tardias) sendo o ponto máximo aconselhado, a metade da linha do leite do grão (30 a 33\% MS).

Segundo Moraes et al. (2008) em termos qualitativos o híbrido de textura dentada é superior ao híbrido de textura dura nos estádios de $1 / 2$ leitoso e $1 / 4$ leitoso quando comparado ao estádio de camada preta com relação a digestibilidade e proteína bruta.

\section{Tamanho de partícula da silagem}

A silagem, quando adequadamente compactada favorece e acelera a fermentação anaeróbia no interior do silo. No entanto, este processo requer alguns cuidados quando o objetivo é a redução de perdas e garantia de uma silagem de qualidade, a exemplo do tamanho de partícula do material colhido, o qual deve ser picado em partículas de 2 e 2,5 cm antes de seu transporte para o silo (Tomich et al., 2003), garantindo a anaerobiose.

A picagem facilita a acomodação do material dentro do silo, além de expor os carboidratos solúveis e facilitar a ação dos microorganismos fermentadores. Tamanhos de partículas menores, principalmente abaixo de 0 , $5 \mathrm{~cm}$, prejudicam a ruminação, reduzem o consumo voluntário de silagens e a digestão das fibras. Segundo Passini et al. (2004) o tamanho de partícula influencia os padrões de fermentação ruminal, produção microbiana e eficiência da utilização do amido e de outros nutrientes no rúmen.

Portanto, o tamanho de partículas da silagem assume papel importante no controle do consumo e posterior desempenho animal. Para isso, torna-se necessário o ajuste de máquinas que façam a colheita adequada da forragem, pois o sucesso da ensilagem é dependente dessa etapa. 
A exemplo, Garbuio et al. (2006) avaliando o efeito da colhedora de Forragem JF 92 Z10 regulada para proporcionar cinco tamanhos de partículas sobre 10 híbridos de milho com texturas duras a dentadas, concluíram que para um mesmo tamanho de fragmento da ensilagem, são necessárias diferentes regulagens da colhedora de forragens conforme o híbrido escolhido em virtude de sua textura.

Cabe ressaltar que a colhedora não somente colhe a planta, como também promove a picagem da planta em tamanho satisfatório para ocorrência de uma fermentação de qualidade e, posterior aceitabilidade pelos animais mas, para isso, essa etapa do processo requer energia.

\section{Consumo de energia na colheita}

A eficiência dos sistemas de conservação de forragens não deve ser avaliada somente pelo valor nutritivo do produto final, mas também pelos custos por $\mathrm{kg}$ de massa seca produzida. Segundo Green et al. (1985) a elevação dos custos de produção e a queda dos preços dos produtos agrícolas no mercado têm incentivado os produtores a buscar mecanismos eficientes com baixos custos de produção, dentre eles, o uso de máquinas.

Normalmente, a condução da lavoura (plantio a colheita) de milho é a mais onerosa, correspondendo a 60 - 65\% do custo total de produção, estando a ensilagem na faixa de 35 a 40\%. Estes valores dependem de vários fatores, com destaque para o tipo e eficiência das máquinas e equipamentos. O custo de produção está diretamente relacionado à produtividade da cultura, sendo esse um dos itens mais importantes na escolha da cultivar (Miranda et al., 2008).

As perdas físicas intrínsecas ao processo de ensilagem, a exemplo da perda de forragem no campo durante a colheita tornan-se significativas quando em estádios de colheita mais avançados. Assim, a ensilagem deve ser feita de forma a proporcionar baixos custos de produção para que seja viável sua utilização, aliando-se o processamento deste material a estádios de 
FACTORI, M.A. et al. Silagem de planta inteira de milho: pontos importantes a serem considerados. PUBVET, Londrina, V. 6, N. 17, Ed. 204, Art. 1368, 2012.

colheita que proporcionem menor custo e maior viabilidade por $\mathrm{kg}$ de massa seca produzida.

Segundo Silva (1997), a maximização do uso do trator agrícola e seus implementos, torna-se fundamental na redução de custos de produção para aumentar a eficiência do combustível de modo que produza máxima quantidade de trabalho por unidade consumida. Segundo Mialhe (1996), os tratores agrícolas têm seu desempenho avaliado pela potência na TDP (Tomada de Potência) e pelo consumo de combustível.

Estudos conduzidos por Seki (2007) com o objetivo de quantificar a demanda energética no processo de ensilagem de milho indicaram baixo consumo horário de combustível $\left(7,40 \mathrm{~L} \mathrm{~h}^{-1}\right)$ e alto consumo de combustível por área $\left(34,2 \mathrm{~L} \mathrm{ha}^{-1}\right)$, devido à baixa capacidade operacional do equipamento. A velocidade de deslocamento do conjunto trator-equipamento foi reduzida devido ao grande volume do material a ser processado, visto que, o aumento da velocidade de deslocamento, proporciona o aumento das perdas por tombamento de plantas e do tamanho das partículas da forragem processada.

De acordo com a energia gasta para redução da partícula na colheita, essa é decorrente do grau de dureza, da película de cada produto e das características de moagem de qualquer grão triturado (Conceição, 1984; citado por Seki, 2007). Factori et al. (2008) trabalhando com moagem de grãos de milho de textura dentada e dura concluíram que em granulometria de menor Diâmetro Geométrico Médio (DGM) de $570 \mathrm{~mm}$ deve-se dar preferência por grãos de milho de textura dentada devido ao menor consumo de energia elétrica $(13 \%)$ em comparação com os grãos de milho de textura dura.

Para tanto, pesquisas que abordem o consumo de combustível na colheita de diferentes híbridos, estádios e tamanhos de partículas, podem inferir novos conceitos, sobretudo na escolha do melhor momento que vise eficiência no campo até o produto final, seja ele carne, leite ou outro, diminuindo os custos dos sistemas de produção. 


\section{Processamento, digestibilidade e degradabilidade}

O que se espera de uma cultivar de milho para silagem, é que os grãos estejam úmidos e macios no momento do corte. Calestine et al. (2001) concluíram que o híbrido de textura dura no estádio de camada preta ou maturação fisiológica, diminui consideravelmente seu aproveitamento sendo que nos estádios dentado inicial e metade da linha do leite as degradações foram semelhantes. Pereira et al. (2004) avaliando os efeitos da textura e do estádio de maturidade sobre a degradabilidade ruminal de grãos de milho concluíram que o efeito da textura sobre a degradabilidade ruminal foi acentuado no estádio de camada preta.

Entretanto, o processamento da forragem a ser ensilada visa melhorar a qualidade do material por meio do tratamento mecânico do grão ou da porção vegetativa. O tratamento mecânico pode ser realizado principalmente pelo esmagamento dos grãos ou cortes para diminuir a fração vegetativa da planta. Segundo Passini et al. (2004) o tamanho de partícula influencia os padrões de fermentação ruminal, produção microbiana e eficiência da utilização do amido e outros nutrientes no rúmen.

O uso de quebradores de grãos nas colhedoras de forragem promove maior aproveitamento e digestibilidade dos grãos com redução na digestibilidade da MS (Zobell et al., 2004), devido à redução do tamanho de partícula, o que indiretamente compromete ou prejudica a ruminação. Existem ainda, em algumas colhedoras automotrizes e, principalmente em máquinas no continente europeu, quites adicionados a estas máquinas que permitem o esmagamento dos grãos de milho com intuito de romper a película que reveste o grão, aumentando seu aproveitamento, sem alterar o tamanho de partícula da forragem (Vita, 2008).

O processamento físico se constitui em estratégia importante para colheita de plantas com avançado estádio de maturação. O benefício do processamento dos grãos da planta de milho com teor de MS inferior a 35\% é mais difícil de prever. $O$ ganho em maior digestibilidade do amido não é tão 
FACTORI, M.A. et al. Silagem de planta inteira de milho: pontos importantes a serem considerados. PUBVET, Londrina, V. 6, N. 17, Ed. 204, Art. 1368, 2012.

pronunciado nestes teores de MS, devido à maior porção leitosa do grão (Bal e Shaver, 1997). Por essa razão, aumentos significativos na produção de leite são esperados quando vacas que recebem silagens processadas onde os grãos apresentam mais da sua metade endurecida. Johnson et al. (1999) indicaram que o processamento de plantas em avançado estádio de maturação, garantiu maior benefício para a fração grãos.

Dhiman et al. (2000) analisando a influência do processamento mecânico (1 mm de tamanho de partícula) na produção de leite de vacas holandesas concluíram que em estádio mais avançados (40\% MS) o processamento foi mais efetivo. O processamento expõe os grãos aos ataques de microorganismos ruminais implicando no maior aporte de carboidratos. Os mesmos autores encontraram valores inferiores para a digestibilidade da MS e proteína bruta (PB) em estádios de $1 / 4$ e 3/4 da linha do leite do grão, por volta de $30 \%$ de MS. Johnson et al. (1999) também verificaram que o processamento aumentou a degradação ruminal com os tratamentos processados em avançados estádios de maturação. Desta forma, a massa ensilada conteria maior proporção de grãos quebrados, melhorando a utilização pelos animais, sendo esta a principal finalidade do processador, quebrar ou esmagar os grãos de milho.

A qualidade de uma forragem pode ser expressa, segundo Orskov (1986), pela extensão da digestão potencial, taxas de fermentação e redução do tamanho da partícula. A técnica da degradabilidade 'in situ' tem sido usada para medir o desaparecimento dos constituintes do alimento contido em sacos de náilon (Mehrez e Orskov, 1977). Após incubação desses sacos na cavidade ruminal, por vários períodos de tempo, obtém-se, por diferença de peso, o desaparecimento de parte da amostra, sendo este como sinônimo de degradação (Castillo Arias, 1992). A técnica do saco de náilon ou da degradabilidade in situ permite o contato íntimo do alimento com o ambiente ruminal, sendo a melhor forma de simulação deste meio, embora o alimento não esteja sujeito a todos os eventos digestivos, como a mastigação, a ruminação e a taxa de passagem (Van Soest, 1994). 
FACTORI, M.A. et al. Silagem de planta inteira de milho: pontos importantes a serem considerados. PUBVET, Londrina, V. 6, N. 17, Ed. 204, Art. 1368, 2012.

Corrêa (2001) avaliando a degradabilidade efetiva da matéria seca observou que, grãos de milho que possuíam maior vitreosidade, ou de textura mais duras, apresentaram menor degradabilidade efetiva no rúmen.

Factori et al. (2008) trabalhando com dois cultivares de milho de textura dentada e dura, verificaram que em estádios mais avançados de colheita, o uso do processamento da planta inteira de milho após a trituração, promoveu aumentos expressivos na degradabilidade ruminal, alcançando até $30 \%$ na degradabilidade da MS, 14 \% para amido e $12 \%$ para proteína, mesmo utilizando o híbrido de textura dentada no estádio de início de camada preta, comumente não recomendado segundo a literatura para ser fornecido para os animais em função do seu menor aproveitamento.

Lopes et al. (2004), observaram pela técnica de degradabilidade, valores menores para a silagem com milho de textura dura com degradabilidade efetiva da MS de 52; 46 e 41\%, respectivamente para as taxas de passagens de $3 ; 5$ e $8 \%$ h-1, respectivamente. A cultivar de milho dentado (AG-1051) apresentou maior degradabilidade efetiva da MS na taxa de passagem de $8 \%$ e menor valor para o híbrido de textura dura (SHS-4040).

Em relação aos tratamentos com materiais que se utilizam de processamentos sobre a forragem, a utilização de uma técnica que vise manter este efeito sobre o material a ser incubado torna-se fundamental para verificar o quanto de benefício foi ganho. Assim, os pesquisadores têm demonstrado preocupação quanto aos efeitos dos procedimentos prévios realizados sobre as amostras dos alimentos. Huntington e Givens (1995) recomendaram não proceder a prévia secagem das amostras de forragens e silagens sendo, portanto, inseridas nos sacos de náilon in natura. A pré-secagem, procedimento obrigatório para obtenção de amostras secas e moídas, quando se utiliza de alimentos úmidos, aumenta os riscos de perdas de compostos solúveis nesses materiais.

Andrae et al. (2001), estudando a ingestão e digestibilidade com novilhos sobre o processamento (moagem fina) e estádios de colheita de híbridos de milho para silagem utilizaram-se da técnica in situ macro bag (amostras in 
FACTORI, M.A. et al. Silagem de planta inteira de milho: pontos importantes a serem considerados. PUBVET, Londrina, V. 6, N. 17, Ed. 204, Art. 1368, 2012.

natura) e verificaram que o processamento aumentou a digestibilidade total do alimento encontrando menor digestibilidade da fibra, em virtude da diminuição da sua efetividade.

\section{Considerações finais}

O efeito das texturas de grãos, tamanhos de partículas, estádios de colheita no consumo de combustível e aproveitamento do material aliado ao processamento na ensilagem de milho pode tornar-se uma ferramenta promissora no aproveitamento deste material, sobretudo na melhoria da eficiência dos diversos sistemas de produção animal.

\section{Referências Bibliográficas}

ANDRAE, J.G.; HUNT, C.W.; PRITCHARD, G.T.; KENNINGTON, L.R.; HARRISON, J.H. Effect of hybrid, maturity, and mechanical processing of corn silage on intake and digestibility by beef cattle. Journal of Dairy Science, Lancaster, v. 79, p. 2268-2275, 2001.

BAL, N.; SHAVER, R. Impact of the maturity of corn for use as silage in the diets of dairy cows on intake, digestion and milk production. Journal of Dairy Science. v.80, p. 2497-2503, 1997.

BARBOSA, R.A.; NASCIMENTO JÚNIOR, D.; EUCLIDES, V.P.B.; SILVA, S.C. da; ZIMMER, A.H.; TORRES JÚNIOR, R.A.A. Capim-tanzânia submetido a combinações entre intensidade e freqüência de pastejo. Pesquisa Agropecuária Brasileira, v.42, p.329-340, 2007.

BLASER, R. Corn silage, a high energy forage. Forage Animal Management Systems. Virginia Polytechnic Institute, p. 53-57, 1969.

CALESTINE, G.A.; PEREIRA, M.N.; BRUNO, R.G.S.; VON PINHO, R.G.; CORREA, C.E.S. Effect of corn grain texture and maturity on ruminal in situ degradation. Journal of Dairy Science, v.84, p.419, 2001. Supplement 1.

CASTILLO ARIAS A.M. Avaliação da degradabilidade ruminal e da digestibilidade intestinal de vários alimentos, utilizando-se a técnica do saco de náilon móvel. Dissertação de Mestrado em Zootecnia.Viçosa: UFV, 1992. 108p.

CORRÊA C.E.S. Silagem de milho ou cana-de-açúcar e o efeito da textura do grão de milho no desempenho de vacas holandesas. 2001. 102f. Tese Doutorado - Universidade Federal de Lavras, Lavras, 2001.

CORREA, C.E.S.; SHAVER, R.D.; PEREIRA, M.N., LAUER, J.G., KOHN, K. Relationship between corn vitreousness and ruminal in situ starch degradability. Journal of Dairy Science, v.85, n.11, p.3008-3012, 2002. 
CRUZ, J. C. Cultivares de milho para silagem. Encontro Nacional dos Estudantes de Zootecnia. Anais... Viçosa, 1998.

CRUZ, J. C.; PEREIRA FILHO, I.A. Cultivares de milho disponíveis no mercado de sementes do Brasil para a safra 2005/2006. 2005. Disponível em: <http://sistemasdeproducao.cnptia.embrapa.br/ > Acesso em: 04/maio/2006.

CRUZ J.C.; CORRÊA L.A.; PEREIRA FILHO I.A.; PEREIRA F.T.F.; GUISCEM J.M.; VERSIANI R.P. Cultivares de Milho disponíveis no mercado de sementes do Brasil para a safra 2004/05, ISSN 0102-0099 Dezembro, 2004 Sete Lagoas, MG.

DEMARQUILLY, C.; ANDRIEU, J. Quelques rappels sur les mesures effectuees pour connaitre la valeur nutritive des ensilages de maïs. In: Colloque maïs ensilage, 1996. Nantes-France, p. 23 - 33, Nantes, 1996.

DEMARQUILLY, C.; DULPHY, J. P. Effect of ensiling on feed intake and animal performance. Proceedings International Meeting on Animal Production from Temperate. Grasslands. Dublin, p.53-61, 1977.

DHIMAN, T. R.; BAL, M. A.; WU, Z.;. MOREIRA,V. R.; SHAVER, R. D.; SATTER, L. D.; SHINNERS, K. J.; WALGENBACH, R. P Influence of Mechanical Processing on Utilizationof Corn Silage by Lactating Dairy Cows 2000. Journal of Dairy Science 83:2521-2528.

FACTORI, M.A. Degradabilidade ruminal de híbridos de milho em função do estádio de colheita e processamento na ensilagem 2008. 40 f. Dissertação (Mestrado) - Faculdade de Medicina Veterinária e Zootecnia, Universidade Estadual Paulista Júlio de Mesquita Filho, Botucatu, 2008.

FACTORI, M.A.; COSTA, C.; BIAGGIONI, M.A.M.; SALEH, M.A.D. Avaliação do consumo de energia elétrica em duas granulometrias de moagem de grãos de milho de textura dentada e dura. Boletim da Indústria Animal, N. Odessa, v.65, n.2, p.83-88, abr./jun. 2008.

GARBUiO, P. W.; WEIRICH NETO, P.H.; DELALIBERA, H. C.; SOUZA, N.M.; LOPES, A. R. C.; PEREIRA, J. R. A. Processamento de plantas inteiras de híbridos de milho (zea mays) para silagem XXXV Congresso Brasileiro de Engenharia Agrícola Anais... CD ROM 31 de julho a 04 de agosto de 2006 - João Pessoa - PB.

GREEN, M. K.; STOUT, B. A.; SEARCY, S. W. Instrumentation package for monitoring tractor performance. Transactions of the ASAE, St. Joseph, v.28, n.2, p.346, 1985.

HUNTINGTON, J.A.; GIVENS, D.I. The in situ technique for studying the rumen degradation of feeds: a review of the procedure. Nutricional Abstracts and Reviews. Series B, Wallingford, v. 65, n. 2, p. 63-93, 1995.

JOBIM, C.C.; BRANCO, A.B.; SANTOS, G.T. Silagem de grãos úmidos na Alimentação de bovinos leiteiros. In: V Simpósio Goiano sobre Manejo e Nutrição de Bovinos de Corte e Leite. Anais... Goiânia - Goiás, maio 2003. p. 357-376.

JOHNSON L. HARRISON, J. H.; HUNT, C.; SHINNERS, K., DOGGETT, C. G.; SAPIENZA. D. Nutritive value of corn silage as affected by maturity and Mechanical process. A comteporary review. Journal of Dairy Science, v.82, p. 2813-2825, 1999.

KOTARSKI, S.F., WANISHA, R.D., THUR, K.K. Starch hydrolysis by ruminal microflora. Journal of Nutrition, 122:178-190, 1992. 
LAVEZZO, W.; LAVEZZO, O.E.N.M.; NETO, O.C. Estádio de Desenvolvimento do milho. Efeito sobre produção, composição da planta e qualidade da silagem. Revista Brasileira de Zootecnia, v.26, n.4, p.675-682, 1997.

LOPES, F.C.F.; CARNEIRO, J.C.; NOVAES L.P.; VIANA, A.C.; POSSAS, F.P.; OLIVEIRA, J.S.; GONÇALVES, L.C. Avaliação da degradabilidade ruminal in situ da matéria seca de silagens de milho (zea mays, I.) com diferentes graus de vitreosidade e com perfil de aminoácidos modificado In: Congresso Brasileiro de Milho e Sorgo, 2004, Campo Grande - MS.

ORSKOV, E.R. Evaluation of fibrous diets for ruminants. In: International seminar on feedig evaluation modern aspects problems-future trends, 1, 1985, Aberdeen. Proceedings... Rowett. Research Institute, 1986. p. 38-41.

PASSINI, R.; BORGATTI, L.M.O.; FERREIRA, F.A.; RODRIGUES, P.H.M. Degradabilidade no rúmen bovino de grãos de milho processados de diferentes formas Pesquisa Agropecuária Brasileira, Brasília, v.39, n.3, p.271-276, mar. 2004.

PEREIRA, M.N.; PINHO, R.G.V.; BRUNO, R.G.S.; CALESTINE, G.A. Ruminal degradability of hard or soft texture corn grain at three maturity stages. Scientia. Agricola. v.61, n.4, p.358363, July/August 2004.

McCULLOUGH, M. E. Silage Research at Georgia Station. University of Georgia, 46p., 1968.

MEHREZ, A.Z.; ORSKOV, E.R. A study of the artificial fiber bag technique for determining the digestibility of feeds in the rumen. Journal of Agricultural Science, Tokyo, v.88, n.3, p.645650, June 1977.

MIRANDA, J.E.C.; RESENDE, $\mathrm{H}$; VALENTE; J.O. SILAGEM DE MILHO. Artigo técnico http://www.cnpgl.embrapa.br/nova/sala/artigos/artigolinha.php?id=40, Acesso 23/08/2008.

MORAES, G.J.; COSTA, C.; MEIRELLES, P.R.L.; OLIVEIRA, K. ; FACTORI, M.A.; ROSALES, L.A.; SANTOS, T.A.B. Podutividade e valor nutritivo das plantas de milho de textura dentada ou dura em três estádios de colheita para silagem. Boletim de Indústia Animal., N. Odessa,v.65, n.2, p.155-166, abr./jun., 2008

NUSSIO, L. G. Cultura de milho para produção de silagem de alto valor alimentício. IV Simpósio sobre nutrição de bovinos. Anais... Piracicaba, 1991.

NUSSIO, L.G.; SIMAS, J.M.C. ; LIMA, M. M. . Determinação do ponto de maturidade do milho para silagem. In: Luiz Gustavo Nussio; Maity Zopollato; José Carlos de Moura. (Org.). Anais... $2^{\circ}$ Workshop sobre milho para silagem. 1 ed. Piracicaba-SP: FEALQ, 2001, v. 1, p. 11-26.

RAMOS, A. P., HERnANDEZ, G. N., CASTAÑEDA, F. G. 2002. Potencial Forrajero de Poblaciones e maíz y relación entre atributos agronómicos con la calidad. Técnica Pecuaria en Mexico. 40 (3):215-228.

SEKI, A.S. Demanda energética no processo de ensilagem de milho, Dissertação (mestrado) - Universidade Estadual Paulista, Faculdade de Ciências Agronômicas, 101 f. Botucatu, 2007.

SILVA, S. L. Projeto e construção de um sistema de aquisição de dados para avaliação do desempenho energético de maquinas e implementos agrícolas. Botucatu, 1997. 148 f. Dissertação (Mestrado em Agronomia / Energia na Agricultura) - Faculdade de Ciências Agronômicas, Universidade Estadual Paulista. 
TOMICH, T.; PEREIRA, L. G. R.; GONÇALVES, L. C. et al. Características químicas para avaliação do processo fermentativo de silagens: uma proposta para qualificação da fermentação. Corumbá: Embrapa Pantanal, 2003. 20 p. (Embrapa Pantanal. Documentos, $57)$.

VAN SOEST, P.J. Nutritional ecology of the ruminant. 2.ed. Ithaca: Cornell University Press. 476p, 1994.

VITA, G. Silagem sob encomenda. Máquinas e Equipamentos, Revista DBO; Abril, 2008. Disponível em: <http://www.mundodoleite.com.br/revistadbo/pdf/mat_2349.pdf;> Acesso. 10/maio/2008.

ZOBELL, D.R.; OLSON, K.C.; WIEDMEIER, R.D. Processed Corn Silage Effects on Digestibility and Production of Growing Beef Replacement Heifers Department of Animal, Dairy and Veterinary Sciences, AG/2004/Beef-03, Fev. 2004. 